\title{
Simulation of Thermal Ablation Process using ANSYS Software
}

\author{
Vijaya Kanth P, Balakrishna Murthy V, Chandra Mohan R
}

\begin{abstract}
An ablation process during the Pyrolysis of an insulating layer used in a thermal protection system is simulated using the commercial software ANSYS in the present work. Two different methods are proposed and established for mutual validation. Both the methods estimate the ablation by successive eliminations of the regions exposed to melting point temperature from a transient thermal analysis with suggested mesh quality and time increments satisfying the convergence of results. Two-dimensional plane models are solved and the effect of burning time and load pattern on ablation is analyzed. The proposed methodology can be used to predict the thermal ablation in thermal protection systems of various space applications.
\end{abstract}

Index Terms: Ablation, FEM, Transient heat transfer, Logarithmic load

\section{INTRODUCTION}

Sacrificing insulating liners are used in rocket motors to protect the base structure from the heat liberated due to combustion of propellant. Rocasin rubber is one such insulating material. Donald M. Curry [1] presented an analytical model using FDM for predicting the transient one-dimensional thermal performance of a charring ablator heat protection system. Ashraf Fathy Ahmed and Suong V Hoe [2] introduced a new method for the development of asbestos free rubbers for use as rocket motor insulators. Mohan Kumar ET all [3] explained the mechanism of ablation and the desirable properties of ablative composites. Pawan Kumar [4] estimated ablation of thermal protection system provided at the inner surface of rocket nozzle using finite element method. Charitha Krishna [5] predicted ablation in a thermal boot of a flex seal of a rocket nozzle using finite element method. In the present work, ablation process due to excessive temperatures in Rocasin rubber is simulated in ANSYS software in order to establish a numerical procedure to predict the ablation in insulating liner of a rocket motor casing.

\section{PROBLEM MODELING}

Finite element models are developed on a two-dimensional geometry of $1 \mathrm{~mm}$ height and $25 \mathrm{~mm}$ length to obtain a semi infinite model. The considered domain is meshed with linear quadrilateral elements. Mesh density (Element edge length $=0.05 \mathrm{~mm}),(10,000$ elements $)$ and time step $(=0.5 \mathrm{~s})$ are selected based on the validation of model for transient response. Two different methods are established and mutually validated for the prediction of thermal ablation

Revised Manuscript Received on November 05, 2019.

Vijaya Kanth P, P.G Student, Thermal Engg., Department of Mechanical Engineering, VRSEC, Vijayawada, Andhra Pradesh, India.

Balakrishna Murthy V, Professor, Department of Mechanical Engineering, VRSEC, Vijayawada, Andhra Pradesh, India.

Chandra Mohan R, Chairman, Resins \& Allied Products, Nidamanuru, Vijayawada, Andhra Pradesh, India. when one end of the model is subjected to a heat flux of 1 $\mathrm{W} / \mathrm{mm} 2$. Material properties are taken from the reference [5]. In the first method, portion of the material acquiring temperatures beyond the melting point is eliminated and the load is shifted to new boundary at specified time intervals during the analysis. In the second method, properties of the material are regulated so as to provide negligible resistance for heat flow in the effected zone. In addition, the two methods are applied to predict the ablation due to a logarithmically decreasing heat with respect to time which is expressed as ' $\mathrm{q}=\mathrm{a}-\mathrm{b}\{\ln (\mathrm{t})\}$ '.

\section{RESULTS}

Temperature distribution along the model at $\mathrm{t}=12 \mathrm{~s}$, obtained from FEM and analytical solution, is shown in Fig. 1. It is observed that considered mesh quality and time increment (element size $=0.25 \mathrm{~mm}$ and $\Delta \mathrm{t}=0.5 \mathrm{~s}$ ) are sufficient to obtain acceptable numerical answer. Fig. 2 and 3 show the variation of predicted ablation with fixed and moving heat source boundary conditions. As there is a vast deviation in the results, moving heat source boundary condition, though not simple to model, is realistic and is required for the accurate prediction of ablation. Fig. 2 shows the temperature contours for fixed and moving heat source boundary conditions. The ablated portion is shown in grey color. Fig. 4 shows the variation of ablation with respect to time predicted from both the methods. At $\mathrm{t}=10 \mathrm{~s}, 2.17 \%$ deviation is observed in the ablation value. Effect of load pattern on ablation is shown in Fig. 5. In logarithmic load the ablation is very low due to reduction of acting heat with respect to time. Fig. 6 shows the comparison of both the methods for logarithmic load. Similar to constant load, 3.5\% variation in ablation at $\mathrm{t}=10 \mathrm{~s}$ is observed.

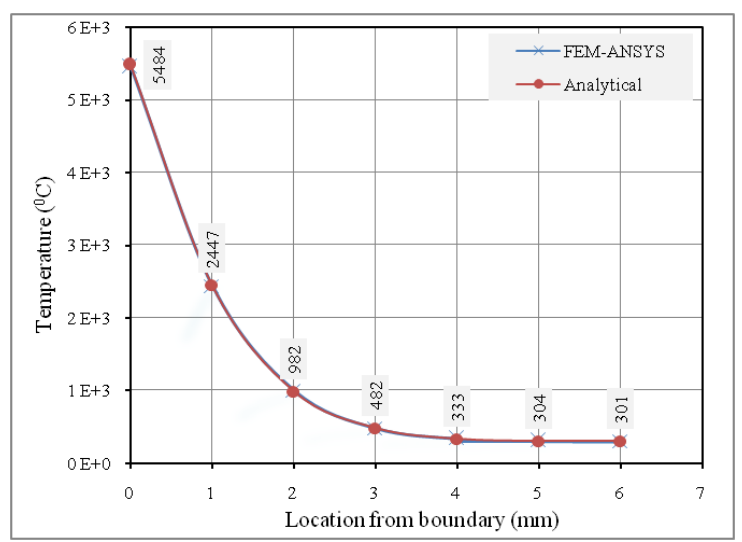

Fig. 1: Validation of FEM result with Analytical Solution 


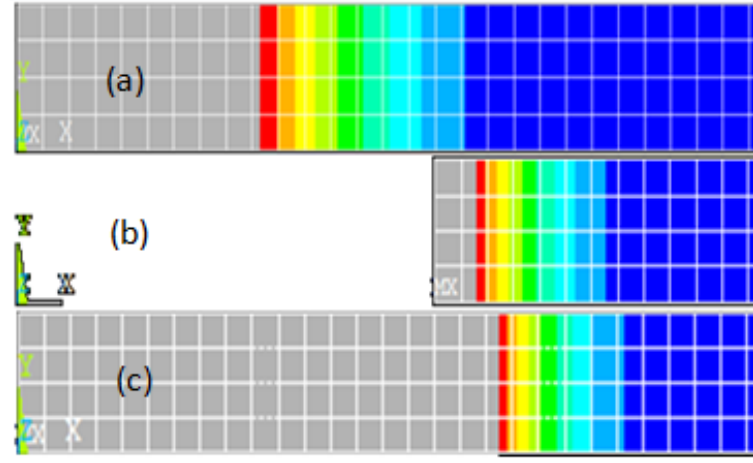

Fig. 2: Temperature Contours (a) Fixed boundary condition (b) Moving boundary condition (M1) (c) Moving boundary condition (M2) at $t=10 s$.

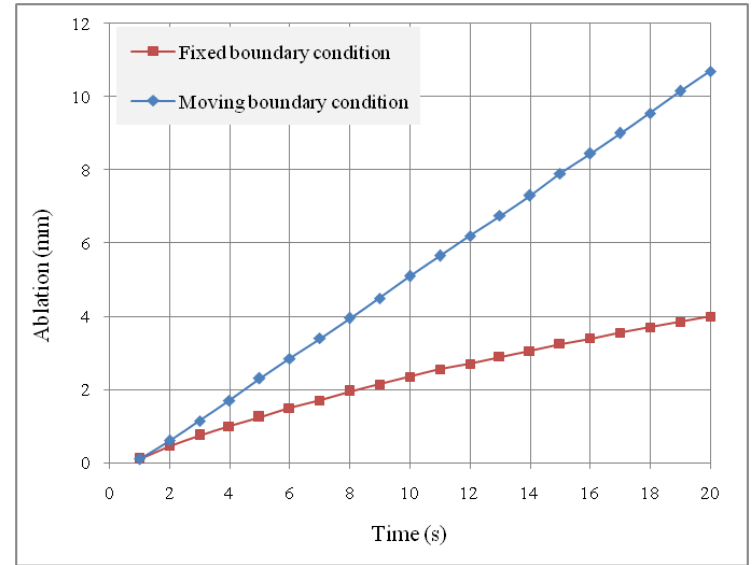

Fig. 3: Fixed Vs moving boundary conditions (constant load)

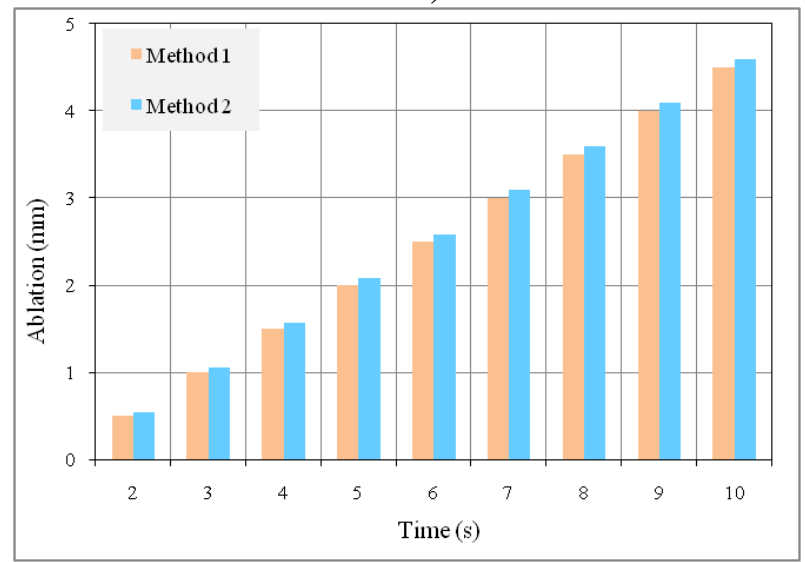

Fig. 4: Comparison of Methods (constant load)

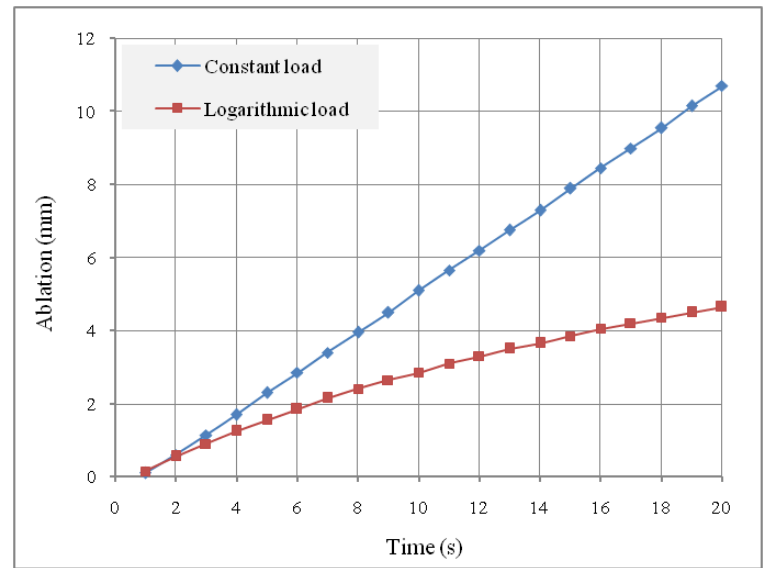

Fig. 5: Constant load Vs Log. load (M2)

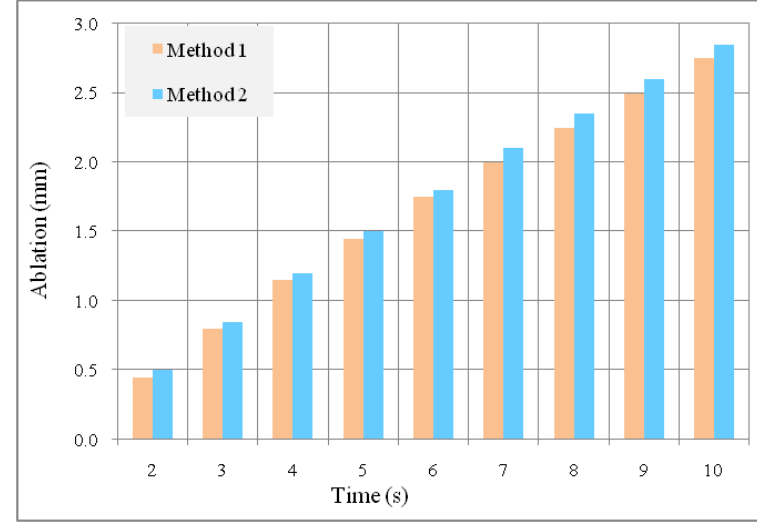

Fig. 6: Comparison of Methods (Log. load)

\section{CONCLUSIONS}

1. Two different finite element simulations are developed and mutually verified for the prediction of ablation in an insulating layer considered in the form of semi-infinite region.

2. It is observed that the percentage variation in both the methods is negligibly small and hence any one method can be used as per the requirement.

3. Method 2 is found to be very simple to apply and requires very less time when compared to Method 1, but not suitable in the presence of mechanical erosion.

\section{REFERENCES}

1. Donald M. Curry, 1965, An analysis of a charring ablation thermal protection system, NASA technical note, D-3150.

2. Ashraf Fathy Ahmed and Suong V. Hoa, 2012, Thermal insulation by heat resistant polymers for solid rocket motor insulation, Journal of Composite Materials, 46, 1549-1559

3. Mohan Kumar L., Anandapadmanabhan EN., Usha KM., Chakravarthy P., 2016, Development, Characterization and Qualification of Aerospace Ablative Composites, International Advanced Research Journal in Science, Engineering and Technology, 3, 87-91.

4. Y. Pawan Kumar, 2017, Finite element simulation of ablation process in a rocket nozzle using ANSYS software, M. Tech. Thesis, Thermal Engineering, V. R. Siddhartha Engineering College.

5. P. Charitha Krishna, 2017, Analysis of thermal protection system in flex seal of a rocket motor" M. Tech. Thesis, Thermal Engineering, V. R. Siddhartha Engineering College. 